Rosé Colom Toldrá1

Maria Teresa Bruni Daldon²

Maria da Conceição dos Santos ${ }^{3}$

Selma Lancman ${ }^{4}$

1 Docente do Curso de Terapia Ocupacional do Departamento de Fisioterapia, Fonoaudiologia e Terapia Ocupacional da Faculdade de Medicina da Universidade de São Paulo e do Laboratório de Investigação e Intervenção em Saúde e Trabalho.

2 Terapeuta Ocupacional do Centro de Referência em Saúde do Trabalhador, Freguesia do Ó, Secretaria Municipal de Saúde de São Paulo.

${ }^{3}$ Docente do Curso de Terapia Ocupacional do Centro Universitário São Camilo e Terapeuta Ocupacional do Laboratório de Investigação e Intervenção em Saúde e Trabalho do Curso de Terapia Ocupacional da Faculdade de Medicina da Universidade de São Paulo.

${ }^{4}$ Professora Titular do Departamento de Fisioterapia, Fonoaudiologia e Terapia Ocupacional do Curso de Terapia Ocupacional da Faculdade de Medicina da Universidade de São Paulo e Coordenadora do Laboratório de Investigação e Intervenção em Saúde e Trabalho.

Contato:

Professora Doutora Rosé Colom Toldrá

Rua Cipotânea, nº 51 - Cidade Universitária.

Cep: 05360-160 - São Paulo - SP

E-mail:

rosetoldra@usp.br

Recebido: 30/06/2009

Revisado: 01/03/2010

Aprovado: $15 / 03 / 2010$

\section{Facilitadores e barreiras para o retorno ao trabalho: a experiência de trabalhadores atendidos em um Centro de Referência em Saúde do Trabalhador -SP, Brasil}

\author{
Facilitating factors and barriers for returning to work - the \\ experience of workers treated at a Workers' Health Reference \\ Center in São Paulo, Brazil
}

\section{Resumo}

Os trabalhadores acometidos por doenças ocupacionais têm vivenciado muitas dificuldades para retornar ao trabalho devido às limitações funcionais e aos obstáculos vivenciados junto às empresas, à previdência social e aos serviços de saúde. Restrição laboral e retorno ao trabalho são aspectos dos mais complexos nas políticas de atenção à saúde do trabalhador. Visando identificar os facilitadores e as barreiras para o retorno ao trabalho de trabalhadores com longo período de permanência e sem resolutividade no serviço, em 2008, realizou-se um estudo exploratório, de natureza empírica, com abordagem qualitativa, desenvolvido a partir de estudo documental de 10 prontuários de trabalhadores acompanhados em grupo pela terapia ocupacional de um Centro de Referência em Saúde do Trabalhador da cidade de São Paulo. A organização e a análise dos dados foram realizadas segundo os componentes da CIF. O uso da CIF favoreceu ampliar a visão das condições de saúde dos trabalhadores e compreender a influência de serviços, sistemas e políticas nas diferentes áreas. As principais barreiras ao retorno ao trabalho foram: ausência de adequados programas de reabilitação profissional e insuficiente comunicação entre os atores dos diferentes níveis administrativos e políticos. Os principais facilitadores foram as atitudes e os comportamentos individuais dos profissionais de saúde do CRST, que forneceram acolhimento e suporte.

Palavras-chave: saúde do trabalhador; retorno ao trabalho; reabilitação profissional; barreiras e facilitadores; terapia ocupacional.

\begin{abstract}
After being affected by occupational diseases, workers face difficulties to return to work due to their functional limitations and obstacles presented by employers, social welfare and health services. Labor restrictions and return to work are complex aspects within worker's health policies. The purpose of this qualitative exploratory study conducted in the second half of 2008 was to identify the facilitating factors and the barriers for returning to work of workers with long unsuccessful treatment. It was based on the documental analysis of 10 clinical records of participants in a occupational therapy group at a Worker's Health Reference Center (CRST) in the city of São Paulo. Data were organized and analyzed according to ICF (International Classification of Functioning, Disability, and Health) components. Working within ICF framework widened our views on workers' health conditions and helped us understand the influence of services, systems, and policies in different areas. Main barriers for returning to work were the lack of adequate occupational rehabilitation programs and the miscommunication among actors at different administrative and political levels. The main facilitator was the individual attitude and the behavior of the CRST staff, providing holding and support to workers.
\end{abstract}

Keywords: worker's health; return to work; occupational rehabilitation; barriers and facilitating factors; occupational therapy. 


\section{Introdução}

Muitas são as dificuldades dos trabalhadores acometidos por doenças ocupacionais para retornar ao trabalho, tanto devido às limitações funcionais decorrentes dos adoecimentos, quanto aos obstáculos vivenciados junto às empresas, ao INSS e aos serviços de saúde. O mundo do trabalho tem sofrido intensas mudanças nos últimos anos com a introdução de novas tecnologias, com as mudanças na organização da produção, com o processo de globalização e a nova ordem estabelecida nas relações entre capital e trabalho, abrindo espaço para novas e conflituosas relações de trabalho, que por sua vez originaram novos processos de adoecimento e novas dificuldades para reabilitação, retorno e, sobretudo, permanência no trabalho.

Como consequência, as situações de desemprego, de subemprego e de trabalho informal tornam-se permanentes e estruturais nas sociedades atuais, favorecendo relações de trabalho precárias que terminam por atingir cada vez mais as condições de trabalho e saúde daqueles que permanecem empregados. Esta nova ordem social induz os trabalhadores assalariados a cederem à precarização das condições de trabalho e às perdas de direitos trabalhistas que dela decorrem, deixando aos trabalhadores a escolha entre um mau trabalho ou trabalho nenhum (LANCMAN; GHIRARDI, 2002). Esta lógica de restrições provoca um impacto na subjetividade dos trabalhadores, ou seja, estes passam a conviver em um mundo onde se perdeu uma série de garantias trabalhistas, direitos adquiridos, conquistas que protegiam não só socialmente, mas psiquicamente as pessoas (LANCMAN; UCHIDA, 2003).

Essas transformações provocam um conflito na vida dos indivíduos que são obrigados a conviver com lógicas de mercado extremamente mutantes, criando uma situação de constante instabilidade e ameaças, que é vivenciada como um mal inevitável dos tempos modernos, cuja causalidade é atribuída ao destino, à economia ou, ainda, às relações sistêmicas (DEJOURS, 1999).

O contexto socioeconômico impõe mudanças no perfil epidemiológico das doenças relacionadas ao trabalho, além de exigir um debate renovado acerca da gênese dessas doenças e de sua gravidade, seja em relação ao número crescente de trabalhadores acometidos, ou em relação ao gradativo processo de exclusão que elas tendem a propiciar.

Vale destacar a importância de se compreender a organização do trabalho e os seus reflexos na problemática de adoecimentos e agravos à saúde dos trabalhadores para pensar a intervenção nos ambientes de trabalho, o tratamento clínico e a reabilitação profissional, a readaptação e a reinserção no trabalho, uma vez que o aumento de adoecimento e de invalidez nos trabalhadores é decorrente de um conjunto de fatores, tais como: carga de trabalho, processos de trabalho insalubres e perigosos, uso de equipamentos e tecnologias obsoletas, ambientes de trabalho inóspitos, problemas relativos à organização do trabalho e às novas formas de divisão do trabalho.

No Brasil, os dados pecuniários do INSS, no ano de 2007 , assinalam que 23,38\% do auxílio doença previdenciário concedido são de doenças do sistema osteomuscular e dos tecidos conjuntivos e 11,86\% são de transtornos mentais e de comportamento. Com relação ao auxílio doença acidentário, no mesmo período, $34,72 \%$ são de doenças do sistema osteomuscular e dos tecidos conjuntivos e somente $2,8 \%$ são de transtornos mentais e de comportamento. Destaca-se que as informações apresentadas pelo INSS referem-se aos dados pecuniários e não epidemiológicos e, portanto, só contabilizam os trabalhadores cadastrados junto a esse órgão, o que corresponde a cerca de $50 \%$ da população economicamente ativa. Em relação aos gastos da Previdência Social, em 2007 (BRASIL, 2008), foram R\$ 5 bilhões em pagamento de auxílios por doença, acidente e aposentadoria.

A restrição laboral e o retorno ao trabalho estão entre os aspectos mais complexos das políticas de atenção à saúde do trabalhador. É necessário pensar a reabilitação profissional para além do que é feito no programa de reabilitação profissional da Previdência Social e da clássica reabilitação clínica oferecida em diferentes serviços de saúde, mas, também, considerá-la como um processo dinâmico de atendimento global do trabalhador que deve envolver as empresas no processo de prevenção, tratamento, reabilitação, readaptação e reinserção no trabalho.

Para melhor compreender a situação vivida por trabalhadores que possuem longo tempo de afastamento e sem resolutividade em um serviço de saúde, optou-se por utilizar a Classificação Internacional de Funcionalidade, Incapacidade e Saúde (CIF) como ferramenta. O modelo da CIF foi proposto pela Organização Mundial de Saúde em 2001 (ORGANIZAÇÃO MUNDIAL DA SAÚDE, 2003). Este modelo faz uma crítica ao modelo médico, centrado na pessoa e na deficiência e propõe um modelo biopsicossocial. No campo da saúde do trabalhador, a CIF permite identificar que as condições sociais, econômicas e políticas observadas nas inúmeras transformações do trabalho são determinantes para as condições de capacidade e incapacidade laborativa.

O objetivo geral da CIF é proporcionar uma linguagem unificada e padronizada e uma estrutura que descreva a saúde e os estados relacionados à saúde. Propõe um modelo de funcionalidade que abrange as estruturas e as funções do corpo, as atividades e a participação, influenciadas pelos fatores ambientais e pessoais. As funções do corpo são consideradas funções fisiológicas dos sistemas orgânicos, tais como, mentais e sensoriais, enquanto que as estruturas do corpo são consideradas partes anatômicas: órgãos, membros e seus componentes.

A classificação entende a incapacidade como um fenômeno que envolve limitações de atividades ou restrição na participação em consequência de um conjunto complexo de condições, muitas das quais criadas pelos fatores ambientais. 
A atividade refere-se à execução de tarefas ou ações, e as limitações de desempenho são as dificuldades que um indivíduo pode encontrar na execução de atividades. Participação é o envolvimento em uma situação de vida e as restrições são as barreiras que uma pessoa pode experimentar nesse envolvimento.

Os fatores ambientais compõem os ambientes: físico, social e de atitudes, nos quais as pessoas vivem e conduzem suas vidas. Os fatores pessoais são as características particulares de um indivíduo e de suas situações de vida, como, por exemplo: gênero, idade, estilo de vida, hábitos, origem social, nível de escolaridade, formação profissional, entre outros.

A funcionalidade abrange todas as funções do corpo e a capacidade do indivíduo de realizar atividades e tarefas relevantes da rotina diária e aquelas relativas à participação na sociedade. A incapacidade envolve as consequências negativas de uma doença ou estado de saúde, como: deficiência nas funções e estruturas corporais, limitações no desempenho das atividades e restrições na participação social. Os processos de incapacidade e funcionalidade são considerados como resultantes da interação de uma condição de saúde com os fatores do contexto.

Assim, o presente estudo visou, por meio do uso da CIF, identificar os facilitadores e as barreiras para a reinserção no trabalho de trabalhadores, acompanhados em grupo pela terapia ocupacional de um Centro de Referência em Saúde do Trabalhador (CRST), com um longo período de afastamento sem resolutividade e contribuir com o uso desta ferramenta para o levantamento e a compreensão das demandas dos trabalhadores.

\section{Material e métodos}

Trata-se de um estudo exploratório, de natureza empírica, com abordagem qualitativa desenvolvida a partir de um estudo documental de prontuários de trabalhadores que foram acompanhados em um CRST na cidade de São Paulo.

O estudo documental analisou os registros dos prontuários de trabalhadores atendidos em grupo pela terapia ocupacional, no segundo semestre de 2008, que visava auxiliar a transição entre os longos períodos de afastamento, potencializar o retorno e a reinserção no trabalho. O critério de escolha deste grupo foi o longo tempo de permanência de seus integrantes no CRST sem resolutividade. A população do estudo foi constituída por 10 trabalhadores em situação ocupacional como afastados ou desempregados, de ambos os sexos, com idades entre 35 e 55 anos.

Para iniciar o levantamento dos dados nos prontuários criaram-se 8 categorias, a priori, baseadas nas temáticas recorrentes que emergiram nos encontros do grupo durante o acompanhamento: (i) dificuldades para o retorno ao trabalho; (ii) expectativas para o retorno ao trabalho; (iii) potencialidades para o trabalho; (iv) fato- res nocivos à saúde passíveis de transformação; (v) estratégias de enfrentamento; (vi) perspectivas de retorno ao trabalho, formal ou informal; (vii) aspectos positivos do processo de retorno ao trabalho; (viii) aspectos negativos do processo de retorno ao trabalho.

A ordenação das informações coletadas foi distribuída em quadros segundo as categorias da CIF (ORGANIZAÇÃ̃O MUNDIAL DA SAÚDE, 2003, p. 22): (i) funções e estruturas do corpo, (ii) atividades e participação, (iii) fatores ambientais e (iv) fatores pessoais (idade, gênero, grau de escolaridade, ocupação). Foi usado o checklist da CIF para a codificação em primeiro nível. Para avançar nos demais níveis de codificação foi usada a CIF completa.

As categorias da CIF levantadas no estudo foram identificadas por estruturas "s" (structure), as funções por "b" (body function), as atividades e a participação por "d" (domain) e os fatores contextuais (ambientais e pessoais) por "e" (environment), segundo a classificação.

\section{Resultados}

Nos resultados do estudo são apresentados os domínios e os componentes da CIF mais relevantes para descrever a experiência de saúde destes trabalhadores. Dos dados disponíveis nos prontuários, foi possível a codificação até o segundo nível.

Conforme o Quadro 1, consideraram-se os dados pessoais que melhor indicavam as repercussões nas condições de vida dos trabalhadores.

Dentre os trabalhadores do grupo, 6 são do sexo masculino e 4, do sexo feminino, com idade que variou de 35 a 55 anos, com baixa escolaridade, sendo a sua maior parte com 1ำ grau incompleto e sem formação profissional qualificada.

Quanto ao ramo de atividade de origem, predominaram aquelas relacionadas aos esforços físicos e à repetição de movimentos. Quanto à situação ocupacional dos trabalhadores, 5 estavam em situação de desemprego, 5 estavam com afastamento do trabalho pelo INSS, sendo que 1 retornou ao trabalho em situação considerada favorável, após afastamento, enquanto participava do grupo.

Os trabalhadores estudados apresentaram alterações das estruturas do sistema nervoso central e das relacionadas ao movimento. Em relação às funções do corpo encontraram-se afetadas as funções mentais, sensoriais, a dor e as funções neuromusculoesqueléticas e relacionadas com o movimento. Os qualificadores em relação à gravidade do problema variaram de grave (50\%-95\%) a um problema completo (96\%-100\%), conforme escala negativa proposta pela CIF para indicar a extensão ou a magnitude de uma deficiência.

As afecções das funções mentais aliadas às alterações das funções neuromuscolesqueléticas e relacionadas ao movimento e à função da dor (Tabela 1) revelaram que os acometimentos são múltiplos. 
Quadro 1 Componentes e domínios da CIF segundo os fatores pessoais, a situação ocupacional e pecuniária e a condição de saúde dos trabalhadores dos participantes do estudo do CRST-SP, 2009

\begin{tabular}{|c|c|c|c|c|c|c|c|c|c|c|}
\hline & Sexo & Idade & Escolaridade & $\begin{array}{l}\text { Formação } \\
\text { profissional }\end{array}$ & $\begin{array}{l}\text { Ramo de } \\
\text { atividade }\end{array}$ & $\begin{array}{c}\text { Situação } \\
\text { ocupacional }\end{array}$ & $\begin{array}{l}\text { Beneficio } \\
\text { recebido* }\end{array}$ & $\begin{array}{l}\text { Situação do } \\
\text { benefício }\end{array}$ & $\begin{array}{l}\text { Tempo de } \\
\text { afastam. } \\
\text { (meses) }\end{array}$ & CID $10^{\text {**** }}$ \\
\hline 1 & M & 49 & 1o grau inc. & Nenhuma & $\begin{array}{l}\text { Cortador de } \\
\text { árvore }\end{array}$ & Desempregado & $\begin{array}{l}\text { B-91 } \\
\text { B-31 }\end{array}$ & Cessado & 68 & $\begin{array}{l}\text { S33.5, M99.8, } \\
\text { M79.8, M79.1, } \\
\text { M77.1, M51, } \\
\text { M51.2, M51.8, } \\
\text { R25.2 }\end{array}$ \\
\hline 2 & M & 49 & 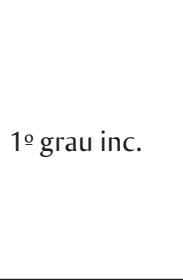 & Nenhuma & Padeiro & Afastado & B-91 & Cessado & 43 & $\begin{array}{l}\text { M17, M23.5, } \\
\text { M23.6, } \\
\text { M25.4, M25.8, } \\
\text { M51, M51.8, } \\
\text { M79.41, } \\
\text { S83.2, S83.5, } \\
\text { M85.6, M94, } \\
\text { M99.8 }\end{array}$ \\
\hline 3 & $\mathrm{~F}$ & 41 & 10 grau inc. & Nenhuma & Costureira & Desempregado & B-31 & Cessado & 60 & M51, M79.1 \\
\hline 4 & M & 35 & 1o grau inc. & Nenhuma & $\begin{array}{l}\text { Ajudante } \\
\text { geral em } \\
\text { construção } \\
\text { civil }\end{array}$ & Afastado & B-91 & Cessado & 27 & $\begin{array}{l}\text { M19.1, M43.1, } \\
\text { M51.1, M51.2, } \\
\text { M54.5, M54.4, } \\
\text { M65.5, M79.1 }\end{array}$ \\
\hline 5 & M & 55 & 1o grau inc. & Nenhuma & $\begin{array}{l}\text { Ajudante de } \\
\text { expedição }\end{array}$ & Desempregado & B-31 & Ativo & 33 & M51.8, M79.1 \\
\hline 6 & $\mathrm{~F}$ & 44 & 2o grau comp. & $\begin{array}{l}\text { Curso técnico } \\
\text { auxiliar de } \\
\text { Enfermagem }\end{array}$ & $\begin{array}{l}\text { Auxiliar de } \\
\text { enfermagem }\end{array}$ & Desempregado & B-31 & Cessado & 31 & $\begin{array}{l}\text { M48.9, M51.8, } \\
\text { M79, }\end{array}$ \\
\hline 7 & M & 38 & 1o grau inc. & Nenhuma & $\begin{array}{l}\text { Alimentador } \\
\text { de linha de } \\
\text { produção }\end{array}$ & Afastado & $\begin{array}{l}\text { B-31 } \\
\text { B-91 }\end{array}$ & Ativo & 28 & $\begin{array}{l}\text { M48.0, M51.8, } \\
\text { M79.1, M99.5 }\end{array}$ \\
\hline 8 & M & 50 & 2o grau comp. & Nenhuma & Digitador & Afastado & B-91 & Ativo & 84 & $\begin{array}{l}\text { M51.8, M65.8, } \\
\text { M79.1, E56.0 } \\
\text { F32.11, F33.2, } \\
\text { F34.1, F43 }\end{array}$ \\
\hline 9 & $\mathrm{~F}$ & 45 & 10 grau inc. & Nenhuma & $\begin{array}{l}\text { Auxiliar de } \\
\text { limpeza }\end{array}$ & Trabalhando & B-31 & Cessado & 8 & $\begin{array}{l}\text { M17, M19, } \\
\text { M51.8, M54.5, } \\
\text { M79.0, M79.1 }\end{array}$ \\
\hline 10 & $\mathrm{~F}$ & 45 & 10 grau inc. & Nenhuma & $\begin{array}{l}\text { Linha de } \\
\text { produção } \\
\text { - montagem } \\
\text { de rádios }\end{array}$ & Desempregado & B-31 & Cessado & 76 & $\begin{array}{l}\text { M51, M67.0, } \\
\text { M70.8, M75.1, } \\
\text { M75.5, M79.1, } \\
\text { F32, F43 }\end{array}$ \\
\hline
\end{tabular}

${ }^{*}$ Benefício recebido: B31 = Doença comum, B91 = Doença Ocupacional ou Acidente de Trabalho

***: CID 10 = códigos da Classificação Internacional de Doenças, $10^{\underline{a}}$ versão 
Tabela 1 Componentes e domínios da CIF segundo as funções e as estruturas do corpo afetadas nos trabalhadores participantes do estudo do CRST-SP, 2009

\begin{tabular}{|c|c|c|}
\hline \multicolumn{2}{|c|}{ Componentes e domínios da CIF } & $N$ \\
\hline \multicolumn{3}{|c|}{ Estruturas do corpo } \\
\hline \multicolumn{3}{|c|}{ Estruturas do sistema nervoso } \\
\hline s 120 & Medula espinhal e estruturas relacionadas & $2 / 10$ \\
\hline \multicolumn{3}{|c|}{ Estruturas relacionadas ao movimento } \\
\hline s710 & Estrutura da região da cabeça e do pescoço & $4 / 10$ \\
\hline s720 & Estrutura da região do ombro & $7 / 10$ \\
\hline s730 & Estrutura do membro superior & $7 / 10$ \\
\hline s740 & Estrutura da região pélvica & $4 / 10$ \\
\hline s750 & Estrutura do membro inferior & $5 / 10$ \\
\hline s760 & Estrutura do tronco & $7 / 10$ \\
\hline s770 & $\begin{array}{l}\text { Estruturas musculoesqueléticas adicionais } \\
\text { relacionadas ao movimento }\end{array}$ & $10 / 10$ \\
\hline
\end{tabular}

Funções do corpo

Funções mentais

Funções mentais globais

b126 Funções do temperamento e da personali-

Estabilidade psíquica, disposição para viver novas experiências, otimismo, confiança, confiabilidade.

Funções mentais que produzem vigor e força e que produzem os incentivos para agir; a força motriz consciente ou inconsciente para a ação.

b130 Funções da energia e dos impulsos

Qualidade do sono.

b134 Funções do sono

$10 / 10$

Funções mentais específicas

$\begin{array}{ll}\text { b140 } & \text { Funções da atenção } \\ \text { b152 } & \text { Funções emocionais }\end{array}$

Manutenção da atenção.

Relacionadas ao sentimento e aos componentes afetivos dos processos mentais.

Funções sensoriais e dor

Dor

Sensações de dor generalizada ou localizada em uma ou em mais partes do corpo, dor em um dermátomo, dor aguda, dor em queimação, dor imprecisa, dor contínua e localizada; deficiên-

b280 Sensação de dor cias; como mialgia, analgesia e hiperalgesia.

Funções neuromusculoesqueléticas e relacionadas com o movimento

Funções das articulações e dos ossos

b710 Funções relacionadas à mobilidade das articulações

b715 Funções relacionadas à estabilidade das articulações

Funções musculares

b730 Funções relacionadas à força muscular
b735 Funções relacionadas ao tônus muscular
b740 Funções da resistência muscular

Funções relacionadas à amplitude e facilidade de movimento de uma articulação.

Funções de manutenção da integridade estrutural das articulações.

Funções relacionadas à força gerada pela contração de músculo ou de grupos musculares.

Funções relacionadas à tensão presente nos músculos em repouso e à resistência oferecida quando se tenta mover os músculos passivamente.

Funções relacionadas à sustentação da contração muscular pelo período de tempo necessário. 
As condições de saúde apresentadas pelos trabalhadores, diagnosticadas segundo a CID 10 (ORGANIZAÇÃO MUNDIAL DA SAÚDE, 1997), de acordo com o Quadro 1, deveram-se a transtornos de discos intervertebrais, transtornos dos tecidos moles relacionados ao uso excessivo e pressão, mialgias, cervicobraquialgias, lombociatalgias, lesões em ombro, transtornos internos dos joelhos, sinovites e tenossinovites, confirmando a tendência de predomínio das doenças osteomusculares relacionadas ao trabalho (DORT), e corresponderam às alterações das estruturas e das funções do corpo relacionadas ao movimento. Além das DORT, estavam presentes nos trabalhadores diferentes alterações de funções mentais, conforme descritas pela CIF, das quais se destacaram: as funções de temperamento e personalidade, as funções de energia e impulso, as funções do sono, as funções de atenção e as funções emocionais (Tabela 1).

As atividades e a participação que se encontraram limitadas para os trabalhadores em função das consequências das doenças relacionadas ao trabalho (Tabela 2) ti-

Tabela 2 Componentes e domínios da CIF, segundo as atividades e a participação nas áreas da vida afetadas nos trabalhadores participantes do estudo do CRST-SP, 2009

\begin{tabular}{|c|c|c|}
\hline & Componentes e domínios da CIF & $N$ \\
\hline \multicolumn{3}{|c|}{ Mobilidade } \\
\hline \multicolumn{3}{|c|}{ Carregar, mover e manusear objetos } \\
\hline d430 & Levantar e carregar objetos & $10 / 10$ \\
\hline d 440 & Uso fino da mão & $2 / 10$ \\
\hline \multicolumn{3}{|c|}{ Andar e mover-se } \\
\hline $\mathrm{d} 450$ & Andar & $5 / 10$ \\
\hline \multicolumn{3}{|c|}{ Deslocar-se utilizando transporte } \\
\hline $\mathrm{d} 470$ & Utilização de transporte & $9 / 10$ \\
\hline d475 & Dirigir & $4 / 10$ \\
\hline \multicolumn{3}{|c|}{ Cuidado Pessoal } \\
\hline d520 & Cuidado das partes do corpo & $2 / 10$ \\
\hline d540 & Vestir-se & $1 / 10$ \\
\hline \multicolumn{3}{|c|}{ Vida doméstica } \\
\hline \multicolumn{3}{|c|}{ Aquisição do necessário para viver } \\
\hline d620 & Aquisição de bens e serviços & $7 / 10$ \\
\hline \multicolumn{3}{|c|}{ Tarefas domésticas } \\
\hline d630 & Preparação de refeições & $2 / 10$ \\
\hline d640 & Realização das tarefas domésticas & $6 / 10$ \\
\hline \multicolumn{3}{|c|}{ Cuidar dos objetos da casa e ajudar os outros } \\
\hline d6-60 & Ajudar os outros & $1 / 10$ \\
\hline \multicolumn{3}{|c|}{ Relacionamentos interpessoais particulares } \\
\hline $\mathrm{d} 770$ & Relações íntimas & $2 / 10$ \\
\hline \multicolumn{3}{|c|}{ Áreas principais da vida } \\
\hline \multicolumn{3}{|l|}{ Educação } \\
\hline d 820 & Educação escolar & $5 / 10$ \\
\hline d830 & Educação de nível superior & $2 / 10$ \\
\hline \multicolumn{3}{|c|}{ Trabalho e emprego } \\
\hline d850 & Trabalho remunerado & $9 / 10$ \\
\hline \multicolumn{3}{|c|}{ Vida econômica } \\
\hline $\mathrm{d} 870$ & Autosuficiência econômica & $9 / 10$ \\
\hline \multicolumn{3}{|c|}{ Vida comunitária, social e cívica } \\
\hline d920 & Recreação e lazer & $9 / 10$ \\
\hline d940 & Direitos humanos & $10 / 10$ \\
\hline
\end{tabular}


veram reflexo na realização das atividades, o que comprometeu a participação da pessoa nas esferas familiar, social e de trabalho.

Nas atividades, destacaram-se mais especificamente as relacionadas com a mobilidade, presentes em diferentes ações e tarefas e que podem dificultar ou inviabilizar uma jornada de trabalho de oito horas, visto que a maioria dos trabalhadores exercia atividades que exigiam esforço físico elevado, repetição de movimentos, manutenção de posturas antinaturais e ritmo intenso/ acelerado com exigência de produção.

As atividades da rotina de vida doméstica, familiar, trabalho e lazer ficaram influenciadas pelas alterações nas estruturas e nas funções do corpo da maioria dos trabalhadores e levaram a restrições na participação nas principais áreas da vida. A inter-relação entre as áreas principais da vida (educação, trabalho e emprego) e a vida econômica, com os aspectos pessoais, apontaram que a baixa escolaridade e a falta de preparo profissional da maioria dos trabalhadores, somada às limitações funcionais decorrentes da doença, impõem uma realidade não promissora para o retorno ao trabalho e, consequentemente, para a autosuficiência econômica.

Para complementar o espectro dos componentes da CIF nos fatores ambientais (Tabela 3), foram consideradas as barreiras e os facilitadores para a capacidade laborativa e o desempenho no retorno ao trabalho dos participantes do estudo. Para tanto, foi utilizada a escala negativa e positiva proposta pela CIF, que denota o impacto de um fator ambiental como obstáculo ou facilitador, alcançando, neste estudo, qualificadores entre moderado (25\%-49\%) a completo (96\%-100\%) para as barreiras e de moderado (25\%-49\%) a considerável (50\%-95\%) para os facilitadores.

Tabela 3 Componentes e domínios da CIF, segundo os fatores ambientais, caracterizados como facilitadores e como barreiras para os trabalhadores participantes do estudo do CRST-SP, 2009

\begin{tabular}{|c|c|c|c|}
\hline \multicolumn{2}{|r|}{ Fatores Ambientais } & $\begin{array}{c}\text { Facilitadores } \\
N\end{array}$ & $\begin{array}{c}\text { Barreiras } \\
N\end{array}$ \\
\hline \multicolumn{4}{|c|}{ Produtos e tecnologias } \\
\hline e135 & Produtos e tecnologias para o trabalho & & $10 / 10$ \\
\hline \multicolumn{4}{|c|}{ Ambiente natural e mudanças ambientais feitas pelo homem } \\
\hline e225 & Clima & & $1 / 10$ \\
\hline \multicolumn{4}{|c|}{ Apoio e relacionamentos } \\
\hline e310 & Família imediata & $1 / 10$ & $3 / 10$ \\
\hline e320 & Amigos & $1 / 10$ & $1 / 10$ \\
\hline e325 & Conhecidos, companheiros, colegas, vizinhos e membros da comunidade & $2 / 10$ & $3 / 10$ \\
\hline e330 & Pessoas em posição de autoridade & $2 / 10$ & $4 / 10$ \\
\hline e340 & Cuidadores e assistentes pessoais & & $1 / 10$ \\
\hline e355 & Profissionais da saúde & $7 / 10$ & $3 / 10$ \\
\hline e360 & Outros profissionais & & $10 / 10$ \\
\hline \multicolumn{4}{|l|}{ Atitudes } \\
\hline e410 & Atitudes individuais de membros da família imediata & & $2 / 10$ \\
\hline e420 & Atitudes individuais dos amigos & $1 / 10$ & $2 / 10$ \\
\hline e450 & Atitudes individuais dos profissionais de saúde & $6 / 10$ & $6 / 10$ \\
\hline e455 & Atitudes individuais dos profissionais relacionados à saúde" & & $10 / 10$ \\
\hline e460 & Atitudes sociais & $1 / 10$ & $2 / 10$ \\
\hline e465 & Normas, práticas e ideologias sociais & $1 / 10$ & $1 / 10$ \\
\hline \multicolumn{4}{|c|}{ Serviços, sistemas e políticas } \\
\hline e525 & Serviços, sistemas e políticas de habitação & $1 / 10$ & $3 / 10$ \\
\hline e540 & Serviços, sistemas e políticas de transportes & & $1 / 10$ \\
\hline e570 & Serviços, sistemas e políticas da previdência social & $1 / 10$ & $8 / 10$ \\
\hline e575 & Serviços, sistemas e políticas de suporte social geral & $1 / 10$ & $3 / 10$ \\
\hline e580 & Serviços, sistemas e políticas de saúde & $2 / 10$ & $5 / 10$ \\
\hline e585 & Serviços, sistemas e políticas de educação e treinamento & $1 / 10$ & $7 / 10$ \\
\hline e590 & Serviços, sistemas e políticas de trabalho e emprego & $1 / 10$ & $8 / 10$ \\
\hline
\end{tabular}


As condições de trabalho referentes aos produtos e às tecnologias para o trabalho (gerais e de assistência) foram classificadas como barreiras em todos os casos, bem como quanto aos apoios e relacionamentos destacaramse aqueles relativos aos profissionais do INSS também classificados como barreiras. Quanto aos facilitadores, os apoios e os relacionamentos de profissionais da saúde, bem como as atitudes individuais de profissionais da saúde foram os que obtiveram a maior frequência dentre os facilitadores destacados pelos trabalhadores.

Os tratamentos/acompanhamentos dos participantes do estudo foram realizados em diferentes serviços, em geral na área de Fisioterapia e Medicina, e no CRST em atendimentos multiprofissionais. No entanto, apesar de alguns referirem melhoras dos sintomas, a maioria manteve a maior parte das queixas iniciais e a incapacidade para desempenhar as mesmas atividades exercidas antes do acidente ou do início da doença.

O longo período de afastamento dos trabalhadores (84 meses a 8 meses, média de 45,8), de tratamento (96 a 8 meses, média 49,8) e a demora no encaminhamento para a reabilitação profissional, de até 54 meses, bem como o não encaminhamento de outros denotam uma falha de interlocução e de diretrizes entre serviços, sistemas e políticas da previdência social, 8/10; de saúde, 5/10; de suporte social geral, 3/10; de educação e treinamento, 7/10; e de trabalho e emprego 8/10, classificados como barreiras.

\section{Discussão}

O modelo da CIF, ao relacionar estruturas e funções do corpo com atividade, participação e contextos ambientais, permite aos profissionais de saúde e de gestão de serviços uma visão ampliada das condições de saúde dos trabalhadores, que pode ser útil na condução de serviços, sistemas e políticas das diferentes áreas.

A CIF enquanto instrumento de uso na prática dos profissionais pode ser benéfica para a descrição dos fenômenos (CHANÁ; ALBUQUERQUE, 2006), pois proporciona bases para a criação de modelos explicativos e valoriza os diferentes aspectos do processo (VÁZQUEZ-BARQUERO et al., 2001). Permite ainda uma abordagem terapêutica mais abrangente, contribuindo na qualidade e na individualidade da atenção, como também na descrição e na classificação de todo o processo saúde-doença (SAMPAIO et al., 2005). A classificação fornece elementos para avaliações mais objetivas, que podem auxiliar tanto na criação de evidências entre os processos de adoecimento no trabalho, quanto na avaliação de restrições laborais e potencialidades de retorno ao trabalho. Colabora também como indicador para as demandas e as ações de reabilitação do afastamento crônico do trabalho.

No estudo, verificou-se que as alterações nas funções e nas estruturas do corpo levaram a incapacidades nas atividades de mobilidade, cuidado pessoal, vida doméstica e nas áreas principais de vida em decorrên- cia dos acometimentos gerados e/ou agravados pelo trabalho. As áreas principais da vida (educação, trabalho e emprego, vida econômica e vida comunitária, social e cívica) ficaram profundamente afetadas nestes trabalhadores devido ao afastamento prolongado ou à perda do emprego, sendo agravadas pela falta de acesso a programas de melhoria de escolaridade, treinamento e (re)capacitação profissional. Estas condições afetaram a capacidade de manter o emprego atual ou de conseguir um novo, o que repercutiu negativamente na participação social, denotando o desrespeito com os direitos destes trabalhadores como cidadãos.

A trajetória do grupo de trabalhadores mostrou que a procura tardia pelo tratamento, muitas vezes ocasionada pelo medo de perder o emprego ou até pela dificuldade de acesso ao tratamento adequado, conduz, em geral, ao agravamento, à cronificação e ao tratamento tardio, também, encontrado em outros estudos (TOLDRÁ, 1997). Esta situação é seguida de tratamentos sintomáticos, paliativos, iniciados na empresa sem a modificação das condições de trabalho.

A situação destes trabalhadores mostrou um percurso de sofrimento, frustração e baixa resolutividade dos problemas de saúde e de reabilitação profissional e colocou em evidência a necessidade de ações preventivas nos ambientes do trabalho, bem como a necessidade de repensar o retorno ao trabalho sem comprometer ainda mais a saúde, evitando o desemprego e a onerosidade ao sistema previdenciário.

O decreto $\mathrm{n}^{\mathrm{o}}$ 4.729, de 9/06/2003 (BRASIL, 2003), assinala que aos segurados elegíveis para o programa de reabilitação profissional deve-se assegurar a articulação com a comunidade, inclusive mediante a celebração de convênio para a reabilitação física.

A demora no encaminhamento da perícia médica para a reabilitação profissional de 6/10 trabalhadores e o não encaminhamento de 4/10 denota a desarticulação entre os diferentes setores (da saúde e da previdênciareabilitação profissional). Esta constatação reafirma o não cumprimento do decreto com vistas ao reingresso no mercado de trabalho, o que contribuiu para a cronificação das condições destes trabalhadores, dificultando seu retorno e os levando a exclusão.

A situação vivenciada pelos trabalhadores contradiz o que enuncia o decreto, que segundo a Previdência ampliaria o alcance e as ações através de parcerias e da diversificação do atendimento, procurando envolver a comunidade no processo de reintegração do reabilitado no mercado de trabalho através da revitalização do "Programa Reabilita”. Os profissionais deste programa limitam-se aos profissionais médicos peritos e a um orientador profissional (OP) de formação em áreas da saúde ou humanas. Cabe ao perito centralizar a avaliação do potencial laborativo do segurado e ao OP, algumas ações de formação de rede. Este modelo deu margem a inúmeras críticas, principalmente no que se refere à diluição das equipes multiprofissionais e à inespecificidade profissional dos OPs (MAENO, 2001; TAKAHASHI; IGUTI, 2008). Estudos indicam que ações de reabilitação e de retorno 
ao trabalho desenvolvido por equipes profissionais, sob a perspectiva de diferentes saberes técnicos científicos, tiveram resultados positivos (TAKAHASHI; CANESQUI, 2003; SAMPAIO et al., 2005).

Nos casos estudados, o programa de reabilitação profissional vigente demonstrou falta de efetividade. Os trabalhadores que passaram pela reabilitação profissional, no entanto, não tiveram a experiência de realização de cursos para a (re)capacitação profissional e, tampouco, ocorreram negociações/intermediações do INSS com a empresa para a reintegração destes. Houve apenas o envio de ofícios relatando a incapacidade e solicitando a readaptação com ausência de ações presenciais.

A lei no 8.213, de 24/07/1991, art. 89 (BRASIL, 1991b), prevê que a habilitação e a reabilitação profissional e social devem proporcionar ao beneficiário os meios para a (re)educação e a (re)adaptação profissional e social, o que não foi constatado nos casos dos trabalhadores do estudo. Bernardo (2006), em pesquisa realizada em uma agência da previdência social em Belo Horizonte, relata que os beneficiários avaliaram que os cursos realizados pelo INSS não os reabilitava e, inclusive, alguns se mostraram inadequados às sequelas apresentadas. Isto apontou que a reabilitação profissional dever ser repensada a partir do interesse e da capacidade laborativa dos trabalhadores.

A carência de recursos materiais e humanos nos serviços do INSS e nos serviços de saúde, assim como a falta de integração dos diferentes serviços, sistemas e políticas das diferentes áreas, criam barreiras para as mudanças das condições de trabalho que causam adoecimento e para a assistência à saúde e de reabilitação profissional, mostrando a contradição entre a legislação e a realidade.

O afastamento do trabalho por tempo prolongado, segundo alguns autores (tempo acima de 3 meses) (LOISEL et al., 1994; ARNETZ et al., 2003; SHAW et al., 2009), torna-se preditivo de dificultadores para o retorno ao trabalho, principalmente devido ao impacto psíquico do afastamento e do retorno, quando esses implicam em mudanças de posto de trabalho, de função e de status (SCOPEL, 2005).

No presente estudo, o tempo de afastamento médio foi de 45,8 meses (Quadro 1), configurando-se em mais um aspecto de impacto para a falta de resolutividade dos casos. Este é um dado de extrema importância a ser considerado nos serviços e nos programas de atenção à saúde do trabalhador, cuja meta deve ser de minimizar as barreiras para um retorno precoce ao trabalho, quer sejam estas de ordem diagnóstico-assistencial, quer sejam das políticas previdenciárias ou, ainda, de gestão de recursos humanos das empresas. Estas ações devem favorecer o retorno terapêutico e precoce ao trabalho.

De maneira geral, quando os trabalhadores retornam ao trabalho são, por vezes, lotados em funções incompatíveis com o seu quadro clínico-funcional e/ou com a sua formação e qualificação, ou são simplesmente deixados à margem do processo produtivo, ou "encostados", reforçando, às vezes, experiências de fracasso vivenciadas pelos trabalhadores do estudo.
Os trabalhadores do presente estudo manifestaram descrédito em si mesmos e na empresa à qual dedicaram sua força de trabalho, vivenciando o impasse entre o desejo de ter saúde e de viver sem limitações com o medo de retornar a se submeter àquilo que os fez adoecer.

Tendo em vista estas experiências, os participantes do estudo manifestaram receio em retornar às situações de trabalho que provocaram a doença, além de incerteza e ansiedade pela dificuldade de vislumbrar mudanças nas perspectivas de vida. Os mesmos revelaram sofrimento tanto físico, quanto psíquico, gerado pelas condições e relações no trabalho, pela incapacidade para trabalhar decorrente de doenças e sequelas. Assim, a incapacidade transcende o aspecto corporal/individual e afeta, conforme Takahashi e Canesqui (2003), a dimensão social/relacional e psíquica.

Parte das empresas optou pelo desligamento do trabalhador, ora pelo desinteresse e pela falta de proposta de reinserção do trabalhador com restrição laboral, ora pela racionalidade econômica que provocava uma série de dilemas e dificuldades para esta reinserção.

Segundo Vasconcelos e Oliveira (2004), grande parte dos trabalhadores tem no trabalho o único elo social fora do convívio familiar, assim, quando o trabalhador encontra-se fora do seu meio de trabalho, pode haver consequências para a sua saúde mental, pelo significado e reconhecimento social do mesmo e, por conseguinte, a sua falta pode levar à desvalorização social. O sentimento de impotência provoca um alto nível de sofrimento, que é vivenciado pelo trabalhador através de dores físicas e psíquicas (MENEZES, 2007).

Os achados corroboram os dados dos autores acima, que apontam que o trabalho possui uma função psíquica. Segundo Sznelwar et al. (2004), o trabalho é um dos grandes alicerces da constituição do sujeito e da sua rede de significados, uma vez que processos como reconhecimento, gratificação, mobilização da inteligência, além de estarem relacionados à realização do trabalho, estão vinculados à constituição da identidade e da subjetividade. E o contrário, a ofensa, a suspeita, a desqualificação da incapacidade, a violência e a injustiça interferem de forma negativa na identidade pessoal e social do trabalhador (BERNARDO, 2006).

Estes elementos se sobressaíram no estudo quando se verificaram que os comprometimentos manifestados referentes às funções mentais globais e específicas acompanharam as alterações nas funções sensoriais de dor e nas funções neuromusculoesqueléticas, conforme demonstra a Tabela 2, bem como os fatores contextuais referentes ao ambiente: apoio e relacionamentos, atitudes e serviços, sistemas e políticas, de acordo com a Tabela 3.

Desta forma, as pessoas que passam por longos períodos de afastamentos do trabalho ou os desempregados de longa duração possuem dificuldades de estabelecer projetos para seu futuro e perdem relações de pertinência não somente nos ambientes de trabalho, mas também muitas vezes na sua vida privada. 
Neste sentido, Seligmann-Silva (1994) coloca que o sofrimento físico, o sofrimento social e o sofrimento mental são indissociáveis e estão intimamente relacionados com a psicopatologia do desemprego.

A condição de retorno ao trabalho pode provocar nos trabalhadores um sentimento de frustração ou de penalização pelo adoecimento do qual foram vítimas e um processo de exclusão tardia, demonstrando, como pode ser entendido pelo modelo multidirecional e multidimensional da CIF, que as funções mentais podem ser afetadas pelas dificuldades em viver novas experiências, pela falta de otimismo, de confiança, de motivação (ORGANIZAÇÃO MUNDIAL DA SAÚDE, 2003) e de resistência para enfrentar as diversidades das exigências do trabalho, criando, assim, barreiras.

Estudos mostram que os apoios e os relacionamentos, compreendidos na CIF como fatores ambientais, são colocados como aspectos facilitadores para o retorno ao trabalho. Considera-se que a relação dos profissionais da equipe com as chefias dos trabalhadores, a aceitação e o apoio dos colegas de trabalho, bem como da família, são considerados como fatores essenciais para o processo de reinserção no trabalho (SAMPAIO et al., 2005; WATANABE, 2004; GRAVINA; NOGUEIRA; ROCHA, 2003). No presente estudo, constatou-se que a única trabalhadora que retornou ao trabalho relatou compreensão da chefia e de seus colegas em relação às restrições laborais e que, com o apoio recebido, voltou inclusive a estudar.

As barreiras que apareceram como mais significativas para o processo de reabilitação e de retorno ao trabalho foram relativas às atitudes, ao apoio e aos relacionamentos dos profissionais do INSS e dos profissionais de saúde, que reforçavam as incapacidades, mostrando a contradição de serviços, sistemas e políticas. Estes, por sua vez, tornavam-se barreiras para que os trabalhadores pudessem acessar os seus direitos, a manutenção do estado de saúde, de condições de trabalho e de subsistência, de educação e treinamento.

No entanto, não se pode deixar de considerar que outros autores (LIMA et al., 2008) apontam que, dentre os diferentes componentes que fazem parte da CIF, o componente "fatores ambientais" é considerado o mais limitado para a descrição das barreiras e dos facilitadores relativos ao contexto do trabalho, pois não é suficiente para descrever as condições de trabalho que levam ao desenvolvimento e ao agravamento das DORT.

No presente estudo, os fatores ambientais considerados foram: apoio e relacionamento, atitudes, serviços, sistemas e políticas, que possibilitaram identificar aspectos relevantes para a descrição e a compreensão das variáveis pesquisadas. Não foi contemplado, no presente estudo, os demais elementos (produtos e tecnologia; ambiente natural e mudanças ambientais feitas pelo ser humano), dadas as características da pesquisa realizada.

Relatos destacaram que o melhor momento do dia para o trabalhador era quando este se encontrava no Serviço de Saúde, pelo acolhimento e o sentimento de pertencimento advindos das possibilidades de conversar de igual para igual nos grupos de tratamento, tais como grupos de LER/DORT, raquialgia, Liang Gong, dores crônicas, biodança, e nas trocas ocorridas na sala de espera. Assim, o CRST era visto como um elemento facilitador para o enfrentamento do processo de exclusão vivido pelos mesmos, tendo em vista que a atitude profissional não discriminadora de escuta e de cuidado foi identificada pelos trabalhadores como positiva.

Os trabalhadores, além da perda da saúde, do cargo na empresa e, por vezes, do emprego, única fonte de renda, conviviam com outras perdas: da identidade profissional, dos vínculos com colegas de trabalho, do status de trabalhador e das perspectivas de vida.

Conseguir um novo emprego para os trabalhadores do estudo não lhes parecia possível diante do reconhecimento de suas limitações funcionais, da desqualificação profissional e do baixo grau de escolaridade. Desta forma, restava-lhes tentar garantir a sobrevivência através dos chamados "bicos", abrir comércio com familiares, vender salgados, bordar e conseguir prorrogar o recebimento do benefício por afastamento do trabalho ou alcançar a sonhada aposentadoria por invalidez.

Com a interrupção da perspectiva profissional na ocupação original, a reabilitação e a adaptação para um novo cotidiano têm se dado à custa de apoio da rede familiar. $\mathrm{O}$ apoio das redes sociais para reinserção no trabalho vem sendo considerado um elemento importante, quer seja no campo do trabalho formal, seja no informal (MAENO, 2001; AZEVEDO et al., 1998).

Para uma política de reabilitação profissional, de retorno ao trabalho e permanência no trabalho, propõe-se um conjunto de princípios e diretrizes na perspectiva da política de humanização do SUS (BRASIL, 2006) com ações nos diferentes setores e nas práticas profissionais, na forma de construção coletiva, envolvendo os diferentes sujeitos implicados, os vínculos solidários, a autonomia e o protagonismo dos trabalhadores, reconhecendo-os como sujeitos e participantes ativos no processo de produção de saúde e de trabalho.

Ao diminuir os fatores nocivos estruturais e organizacionais do trabalho e as suas consequências negativas, está-se contribuindo para a melhoria das condições de saúde dos trabalhadores, para a compreensão dos mecanismos que levam às aposentadorias precoces e à exclusão do trabalho, repercutindo de forma positiva na economia nacional e nos sistemas de saúde e de previdência social.

As ações devem ser voltadas para a transformação de situações de trabalho, sejam elas dirigidas para a prevenção de doenças vinculadas ao trabalho, para o tratamento e/ou reabilitação, ganhando um novo olhar a partir da compreensão de que, se o trabalho é gerador de doenças e sofrimento, qualquer ação que vise a sua transformação ou vise amenizar o sofrimento dos trabalhadores adoecidos ou em risco de adoecimento deve ser pensada a partir de mudanças na relação das pessoas com o seu trabalho, ou seja, com o ato de trabalhar. 
Esse processo de retorno ao trabalho deve envolver mudanças na organização do trabalho (como a redução do ritmo de trabalho, o aumento do número de trabalhadores, a modificação do conteúdo das tarefas, a mudança na dinâmica das relações interpessoais e da estrutura hierárquica), que, na perspectiva da CIF, correspondem aos fatores ambientais.

Na perspectiva de cuidar e resguardar a saúde do trabalhador, em casos de adoecimento e de retorno ao trabalho, deve-se considerar a compatibilidade das tarefas a serem realizadas e as restrições do trabalho às condições clínicas. Na prática, isso implica em: estabelecimento de tarefas de acordo com a capacidade do trabalhador; adequação do ambiente de trabalho e da organização do trabalho; envolvimento efetivo das empresas (através da equipe de saúde e segurança no trabalho e dos recursos humanos); informação, orientação e apoio das chefias e dos colegas a respeito das restrições do trabalhador e o acompanhamento na realização das tarefas. Vale dizer que o retorno a mesma situação de trabalho ou os casos de mudanças de função sem o respaldo de uma adequada política de readaptação podem levar à piora da sintomatologia e a novos afastamentos.

Cabe mencionar os limites do centro de referência onde se deu o estudo quanto à contribuição no processo de retorno ao trabalho, uma vez que legalmente o papel de (re)adaptação, reabilitação profissional e de negociação é de competência da Previdência Social e, ainda, quanto à necessidade de ampliação das ações dos CRSTs em vigilância em saúde do trabalhador nos ambientes de trabalho dos usuários atendidos para criar uma melhoria das condições de trabalho. No entanto, observa-se que nem sempre as vigilâncias em saúde do trabalhador contemplam as empresas de origem dos trabalhadores afastados atendidos no serviço, o que impede um processo continuum de prevenção e de promoção de saúde nestes locais.

Apesar das limitações de um estudo descritivo e com número restrito de participantes, acredita-se que seus dados permitem refletir sobre as questões que podem ser comuns aos trabalhadores com demandas semelhantes, atendidos em outros serviços de saúde.

Outro limite detectado no estudo foi a ausência de normatização nos registros dos prontuários, o que impossibilitou avançar na codificação da CIF no terceiro e no quarto níveis para a funcionalidade e a incapacidade (parte 1), bem como, na parte 2 (fatores contextuais) avançar nos códigos dos qualificadores.

\section{Referências}

ARNETZ, B. B. et al. Early workplace intervention for employees with musculoskeletal-related absenteeism: a prospective controlled intervention. Journal of Occupational and Environmental Medicine, v. 45, n. 5, p. 499-506, May 2003.

\section{Considerações finais}

A CIF forneceu, neste estudo, subsídios para uma visão mais abrangente, integral, articulada e sistematizada das informações referentes aos diversos componentes de saúde e funcionalidade humana que afetam a vida dos trabalhadores, sendo úteis para o desenvolvimento de serviços, sistemas e políticas de reabilitação e para o retorno ao trabalho nas diferentes áreas.

Os resultados mostraram que as principais barreiras para o retorno ao trabalho foram a ineficiência do atual programa de reabilitação profissional, os mecanismos de comunicação insuficientes entre os serviços, sistemas e políticas preventivas, assistenciais e previdenciárias.

Destaca-se que o apoio e os relacionamentos e as atitudes individuais oferecidos pelos profissionais de saúde do CRST foram os principais facilitadores, bem como funcionaram como barreiras à falta de apoio e relacionamentos e às atitudes discriminatórias por parte dos profissionais da Previdência Social.

O estudo mostrou que a precariedade de condições socioeconômicas e de escolaridade dos sujeitos participantes somados aos fatores ambientais dificultaram a (re)educação, a (re)qualificação profissional e a (re)adaptação profissional e social e denunciaram a carência de políticas de valorização da classe trabalhadora.

O longo período de afastamento e de desligamento da rotina do trabalho dá lugar a uma nova rotina, a trajetória de incapacitado para o trabalho, que deve cumprir uma série de compromissos junto aos órgãos de saúde e previdenciários, correndo o sério risco de perpetuação da situação de afastamento e cristalização no papel de doente/segurado.

Nas ações de atenção à saúde do trabalhador, o acolhimento e o reconhecimento do sofrimento presente no processo saúde-doença-trabalho pode melhorar a autoestima e a autoconfiança dos trabalhadores, o que é essencial para a criação de mecanismos positivos de enfrentamento, que refletirão na melhora do desempenho e da funcionalidade.

Ao se garantir condições e ambientes de trabalho adequados, previnem-se o surgimento de novas doenças e a ocorrência de acidentes, ou seja, a construção de uma política de retorno ao trabalho implica em uma política de prevenção de incapacidades.

A articulação eficiente entre os diferentes atores envolvidos, os serviços, os sistemas e as políticas criarão condições satisfatórias para o retorno ao trabalho dos trabalhadores em fase de readaptação profissional.

AZEVEDO, J. T. et al. As estratégias de sobrevivência e de busca de emprego adotadas pelos desempregados. Cadernos de Psicologia Social do Trabalho, São Paulo, v. 1, p. 15-42, dez. 1998. 
BERNARDO, D. L. Os significados do trabalho e da reabilitação profissional para o trabalhador incapacitado para o exercício da profissão habitual. 2006. 72 f. Dissertação (Mestrado em Saúde Pública)Faculdade de Medicina, Universidade Federal de Minas Gerais, Belo Horizonte, 2006.

BRASIL. Ministério da Previdência Social. Anuário Estatístico da Previdência Social 2007. Disponível em: <http://www1.previdencia.gov.br/aeps2007/16_01_03_ 01.asp>. Acesso em: 11 nov. 2008.

. Decreto № 4.729 - de 9 de junho de 2003 - DOU de 10/6/2003. Altera dispositivos do Regulamento da Previdência Social, aprovado pelo decreto $\mathrm{n}^{\circ}$ 3.048, de 6 de maio de 1999, e dá outras providências. Disponível em: < http://www3.dataprev. gov.br/sislex/paginas/23/2003/4729.htm > . Acesso em: 04 maio 2009.

. LEI № 8.213, de 24 de julho de 1991b - DOU DE 14/08/1991. Dispõe sobre os Planos de Benefícios da Previdência Social e dá outras providências. Disponível em: <http://www010.dataprev.gov.br/ sislex/paginas/42/1991/8213.htm $>$. Acesso em: 11 nov. 2008.

Ministério da Saúde. Secretaria de Atenção à Saúde. Núcleo Técnico da Política Nacional de Humanização. Humaniza SUS: documento base para gestores e trabalhadores do SUS. 3. ed. Brasília: Ministério da Saúde, 2006. (Série B. Textos Básicos de Saúde). Disponível em: <http://bvsms.saude.gov. br/bvs/publicacoes/documento_base.pdf > . Acesso em: 10 nov. 2008.

CHANÁ, P.; ALBUQUERQUE, D. La Clasificación Internacional del Funcionamiento, de la Discapacidad y de la Salud (CIF) y la práctica neurológica. Revista Chilena de Neuro-psiquiatria, Santiago, v. 44, n. 2, p. 88-97, jun. 2006.

DEJOURS, C. A banalização da injustiça social. Rio de Janeiro: FGV, 1999.

GRAVINA, M. E. R.; NOGUEIRA, D. P.; ROCHA, L. E. Reabilitação profissional em um banco: facilitadores e dificultadores no retorno ao trabalho. Revista de Terapia Ocupacional da Universidade de São Paulo, São Paulo, v. 14, n. 1, p. 19-26, set./dez. 2003.

LANCMAN, S.; GHIRARDI, M. I. G. Pensando novas práticas em terapia ocupacional, saúde e trabalho. Revista de Terapia Ocupacional da Universidade de São Paulo, São Paulo, v. 13, n. 2, p. 44-50, maio/ago. 2002.

LANCMAN, S.; UCHIDA, S. Trabalho e subjetividade: o olhar da psicodinâmica do trabalho. Cadernos de Psicologia Social e do Trabalho, São Paulo, v. 6. p. 7990, dez. 2003.

LIMA, M. A. G. et al. Avaliação da funcionalidade dos trabalhadores com LER/DORT: a construção do Core Set da CIF para LER/DORT. Acta Fisiátrica, São Paulo, v. 15, n. 4, p. 229-235, dez. 2008.
LOISEL, P. et al. Management of occupational back pain: the Sherbrooke model. Results of a pilot and feasibility study. Journal of Occupational and Environmental Medicine, England, v. 51, n. 9, p. 597602, Sept. 1994.

MAENO, M. Reinserção de trabalhadores com LER no mercado de trabalho. 2001. 117 f. Dissertação (Mestrado em Saúde Pública)-Faculdade de Saúde Pública, Universidade de São Paulo, São Paulo, 2001.

MENEZES, A. O desemprego e suas conseqüências biopsicossociais. Ciente Fico, Salvador, v. 1, n. 7, 2007. Disponível em: <http://www.frb.br/ciente/ADM/ADM. MENEZES.F1.pdf>. Acesso em: 10 dez. 2009.

ORGANIZAÇÃO MUNDIAL DA SAÚDE. Centro Colaborador da Organização Mundial da Saúde para a Família de Classificações Internacionais. CIF: Classificação Internacional de Funcionalidade, Incapacidade e Saúde. São Paulo: Edusp, 2003.

. CID-10: Classificação Estatística Internacional de Doenças e Problemas Relacionados à Saúde. 10 rev. São Paulo: Universidade de São Paulo, 1997.

SAMPAIO, R. F. et al. Implantação de serviço de reabilitação profissional: a experiência da UFMG. Fisioterapia e Pesquisa, São Paulo, v. 12, n. 2, p. 28-34, 2005.

SCOPEL, M. J. Retorno ao trabalho: trajetória de trabalhadores metalúrgicos portadores de LER/DORT. 2005. 131 f. Dissertação (Mestrado em Psicologia Social e Institucional)-Universidade Federal do Rio Grande do Sul, Porto Alegre, 2005. Disponível em: < http://www. lume.ufrgs.br/bitstream/handle/10183/7233/000497098. pdf? sequence=1>. Acesso em: $10 \mathrm{dez} .2009$.

SELIGMANN-SILVA, E. Desgaste mental no trabalho dominado. Rio de Janeiro: Cortez, 1994.

SHAW, W. S.; PRANSKY, G.; WINTERS, T. The back disability risk questionnaire for work-related, acute back pain: prediction of unresolved problems at 3-month follow-up. Journal of Occupational and Environmental Medicine, United States, v. 51, n. 2, p. 185-194, Feb. 2009.

SZNELWAR, L. I. et al. Análise do trabalho e serviço de limpeza hospitalar: contribuições da ergonomia e da psicodinâmica do trabalho. Revista Produção, São Paulo, v. 14, n. 3, p. 45-57, set./dez. 2004.

TAKAHASHI, M. A. B. C.; CANESQUI, A. M. Pesquisa avaliativa em reabilitação profissional: a efetividade de um serviço em desconstrução. Cadernos de Saúde Pública, Rio de Janeiro, v. 19, n. 5, p. 1473-1483, set./ out. 2003

TAKAHASHI, M. A. B. C.; IGUTI, A. M. As mudanças nas práticas de reabilitação profissional da Previdência Social no Brasil: modernização ou enfraquecimento da proteção social? Cadernos de Saúde Pública, Rio de Janeiro, v. 24, n. 11, p. 2661-2670, nov. 2008.

TOLDRÁ, R. C. Lesões por Esforços Repetitivos: abordagem grupal e corporal. In: CONGRESSO 
BRASILEIRO DE TERAPIA OCUPACIONAL, 5., 1997, Belo Horizonte. Anais... Belo Horizonte, Associação Brasileira de Terapia Ocupacional, 997, p.145-149.

VASCONCELOS, Z. B.; OLIVEIRA, I. D. (Org.). Orientação vocacional: alguns aspectos teóricos, técnicos e práticos. São Paulo: Vetor, 2004.

VÁZQUEZ-BARQUERO, J. L. et al. Clasificación Internacional del Funcionamiento, de Discapacidad y de la Salud (CIF): antecedentes, marco conceptual y estructura. Papeles Médicos, v. 10, n. 4, p. 177-184, 2001.

WATANABE, M. A. reabilitação é possível: um estudo de caso de uma empresa de economia mista. 2004. 206 f. Dissertação (Mestrado em Saúde Coletiva)Faculdade de Ciências Médicas, Universidade Estadual de Campinas, Campinas, 2004. 